\title{
Validation of the Ford score as a measure for predicting the level of emotional and behavioural problems in mainstream schools
}

\author{
Anna Goodman, ${ }^{1}$ and Tamsin Ford ${ }^{2}$
}

1 London School of Hygiene \& Tropical Medicine, London, UK

2 King's College London, London, UK

Corresponding author: Anna Goodman, London School of Hygiene \& Tropical

Medicine, Keppel Street, London, WC1E 7HT, UK (ㅁnna.goodman@1shtm.ac.uk).

Note: this is a personal version, created by Anna Goodman, of the text of the accepted journal article. It reflects all changes made in the peer review process, but does not incorporate any minor modifications made at the proof stage. The complete citation for the final journal article is:

- Goodman A, Ford T. Validation of the Ford score as a measure for predicting the level of emotional and behavioural problems in mainstream schools. Research in Education 2008;80(1):1-14.

Copyright (C) and Moral Rights for this paper are retained by the individual authors and/or other copyright owners 


\begin{abstract}
$\underline{\text { Abstract }}$
Emotional and behavioural difficulties (EBD) are common in children, and forecasting their prevalence in schools is of interest to both academic researchers and local authorities. Percentage of pupils eligible for free school meals is one measure often used for this purpose. The article presents the first independent validation of a simple numerical score, the Ford score, which predicts the level of EBD within schools using routinely collected school variables on eligibility for free school meals, special educational needs, unauthorised absences and permanent exclusions. The research tested the predictive utility of the Ford score in the English sub-sample of the British Child and Adolescent Mental Health Survey, 2004. This gave a sample of 6,379 children aged 5-16 in 3,117 schools, with mental health being assessed through clinician-assigned psychiatric diagnoses and through brief questionnaires filled in by parents, teachers and young people. The Ford score was found to be highly predictive of the level of EBD by all four of these measures, with a linear effect across the whole range. The estimated prevalence of mental disorder rose from about 5 per cent in schools with low Ford scores to around 14 per cent in high-scoring schools. The Ford score was more highly correlated with all measures of EBD than percent-age of free school meals alone. The Ford score's predictive utility did not seem to be further enhanced, however, by adding in an additional measure of local area deprivation. It was concluded that the Ford score represents a simple and up-to-date school EBD predictor which is more accurate than percentage free school meals alone and which is not notably improved by taking account of a schools' area deprivation.
\end{abstract}

\title{
Introduction
}

Around the world, the World Health Organisation calculates that neuropsychiatric conditions represent a disproportionately large percentage of the 'burden of disease' in children and adolescents as compared with adults (WHO, 2003). In Britain, the mental health of children has deteriorated in the past fifty years (Collishaw et al., 2004; Rutter and Smith, 1995) despite a general improvement in their physical health. In this context, mental health has increasingly been recognised as central to child welfare by academics, health service providers and policy makers (Graham, 2000).

Children experiencing emotional distress or challenging behaviour may require collaboration between professionals from a number of different disciplines, including mental health, social work and education. Schools and teachers in mainstream schools see emotional and behavioural difficulties in their pupils as an important area of concern, and recognise that these represent more severe problems than 'general naughtiness' (Daniels et al., 1999). Schools also play a front-line role in supporting children with emotional and behavioural difficulties, given that the services most frequently sought in relation to child mental health problems are education-based (Ford et al., 2007). Supporting children with emotional and behavioural difficulties may require additional resources (Department for Education and Skills, 1997), generally budgeted within the more general framework of schools providing for their pupils with special educational needs (SEN). 
Local authorities provide most of the funding which schools receive for SEN provision. Since 2006/2007 local authorities receive funding for their school budgets in the form of a Dedicated School Grant. Authorities distribute this to schools, using locally agreed funding formulas, created in consultation with their school forums and following the school finance regulations. The aim of these funding formulas is to allocate resources so as to reflect schools' 'additional educational needs' due to social deprivation, a high proportion of pupils with SEN, or a high proportion of pupils with English as a second language (Department for Education and Skills, 2005).

Local authorities display considerable variation in both the composition and the complexity of the funding formulas which they use. Percentage of pupils entitled to free school meals (FSM) has long been the most popular proxy of additional educational needs in schools, and remains very widely used (Department for Education and Skills, 2005; Hendry, 2000; Marsh, 1997). FSM is a popular measure because it is easy to understand, uses routinely collected data, and is correlated with additional education needs, including SEN (Department for Education and Skills, 2007). Another increasingly popular option is the use of small-area measures of deprivation, such as the Indices of Multiple Deprivation (IMD) (Office of the Deputy Prime Minister, 2004). In using such measures, most local authorities assign a deprivation score to each individual pupil (based on the postcode of the pupil's home address), and then average this score across the whole school. With the home address of pupils now routinely collected as part of the pupil-level annual school census, this approach is likely to be still more widely adopted in the future.

A crucially important property of both FSM and IMD is that neither is determined by the school itself. This contrasts with other more 'direct' potential measures such as proportion of students with statemented SEN, whose use in a funding formula might create an undesirable incentive for schools be over-zealous in identifying children with special educational needs (Department for Education and Skills, 2006). Yet while this may represent a compelling advantage in the creation of funding formulas, it cannot be assumed that the same methods will be optimal for other purposes. On the contrary, for academic research, or when forecasting future needs at a local level, it may be desirable to make use of more of all potentially relevant information about schools, including factors such as proportion of pupils with statemented SEN. Conversely, some approaches used by local authority funding formulas may not be available to researchers. In particular, researchers often do not have access to the postcodes of the children in a particular school. In such cases, a variable which can be derived from the school's own postcode may be a useful substitute.

In this article we address these issues, using data from a nationally representative population-based survey of child and adolescent mental health. We present the first independent validation of the predictive utility of a simple numerical score (the Ford score) which combines routinely collected school variables to predict the level of emotional or behavioural difficulties within schools. We also compare the performance of the Ford score with the use of FSM alone. We then examine whether an IMD score based 
on school postcode is predictive of child mental health and, if so, whether it adds to the predictive validity of the Ford score.

\section{$\underline{\text { Methods }}$}

\section{Sample}

This article presents data from the English sub-sample of the 2004 British Child and Adolescent Mental Health Survey (B-CAMHS04). We have restricted our analyses to the English sub-sample because of our reliance of data from the Office for Standards in Education (OfStEd) which is responsible only for English schools, and because of our use of the English Indices of Multiple Deprivation.

Full details of B-CAMHS04 have been reported previously (Green et al., 2005). Briefly, B-CAMHS04 was a cross-sectional survey of the mental health of children and adolescents (henceforth referred to as 'children') aged 5-16 in Great Britain. The British Child Benefit Register was used as a nationally representative sampling frame, employing a clustered design by postal sector. The design and data collection in BCAMHS04 were closely similar to the previous, independent B-CAMHS survey in 1999 (Ford et al., 2003; Meltzer et al., 2000), the data for which were used to create the Ford score (see below).

Of the 10,910 English children selected, information was collected on 7,045 (65 per cent); of the remainder, 843 were non-contacts ( 8 per cent), 2,951 refused or were unable to participate ( 27 per cent) and seventy-one children were ineligible ( 1 per cent). For these 7,045 participating children we had 6,988 parent interviews (99 per cent), 5,281 teacher interviews (75 per cent) and 3,049 interviews with children aged 11-16 (90 per cent). Four hundred and thirty-two (6 per cent) of these pupils had missing or incomplete information about their school address, and a further 111 ( 2 per cent) attended educational establishments such Colleges of Further Education which did not report the four school variables of interest for this analysis. We excluded 67 (1 per cent) children who were attending special schools from the analyses, because special schools are likely to be atypical in the distribution both of emotional and behavioural problems and of the school variables which make up the Ford score. A further fifty-six (1 per cent) pupils were excluded because they did not have an Index of Multiple Deprivation assigned to them or because they were the only observed child in a stratum and so could not be used in analyses adjusting for survey design (see below). This left a main sample of 6,379 children (91 per cent of the original B-CAMHS04 sample) attending 3,117 schools. The mean age of these children was 10.4 years, and 3,104 (49 per cent) were female. This sample included 288 children attending 216 independent schools. The maximum number of study children attending the same school was seventeen; at the other extreme, 1,688 (54 per cent) of schools were attended by only a single study child.

\section{Measures of emotional and behavioural difficulties}


B-CAMHS04 assessed mental health using two measures: the Development and Wellbeing Assessment, or DAWBA (Goodman et al., 2000), and the Strengths and Difficulties Questionnaire, or SDQ (Goodman, 1997, 2001).

The DAWBA is a multi-informant semi-structured interview designed to be administered by trained lay interviewers. It consists of a mixture of open and closed questions about child psychiatric symptoms and their impact, with the open-ended questions being used to elicit detailed verbatim descriptions of any problem areas (Goodman et al., 2000). In B-CAMHS04 the DAWBA was completed by parents, teachers and children aged 11-16. A small team of experienced child psychiatrists reviewed the answers to both the closed and the open questions from all available informants in order to make a single decision about whether each child should receive a psychiatric diagnosis and, if so, what that diagnosis should be. In this way the B-CAMHS survey sought to emulate the sophisticated judgements which mental health professionals make in clinical practice. Diagnoses were made according to the International Classification of Diseases (ICD-10) (WHO, 1993), and represent the extreme end of the range of emotional distress and challenging behaviour found in childhood. DAWBA diagnoses were available for all 6,379 children in these analyses.

The SDQ is a well validated twenty-five-item questionnaire with subscales relating to children's emotions, behaviour, activity level, peer relationships and pro-social behaviour. All but the last of these subscales are used to generate a total difficulties score (scored 0-40), which functions as a dimensional measure of emotional and behavioural difficulties (Goodman, 1997, 2001). In B-CAMHS04 the SDQ was administered separately to parents, teachers and children aged 11-16. Parent SDQs were available from 6,340 parents ( 99 per cent of those in the sample), 5,044 teachers (79 per cent of those in the sample) and 2,761 children (88 per cent of those in the sample aged 11-16).

\section{Creation of the Ford score}

The Ford score was originally developed using data from the previous B-CAMHS survey in 1999 as a school-level predictor of mental health. It was created by using multiple linear regression to determine which of fourteen potential school variables (routinely returned data, academic attainment in national tests and school characteristics from OfStEd inspections) best predicted the level of emotional and behavioural difficulties in each school (Ford and Goodman, 2005). The final version of the Ford score consists of four variables which are reported annually by schools to the Department of Children, Schools and Families (DCFS) (formerly known as the Department for Education and Skills). These four variables, and the bandings and scores used to create the Ford score from them, are presented in Table 1. We generated the Ford scores used in this article using data collected in the 2003/04 academic year, as it was within that year (April-July 2004) that the B-CAMHS04 survey took place. The schools in our survey were linked to these variables by using the school postcode to look up each school's Unique Reference Number (URN), which in turn was matched within OfStEd or DCFS databases. Because some postcodes contain several schools, all school names were checked to ensure that correct matches had been made. 
Table 1: The banding and scores for the variables used to create the Ford score

\begin{tabular}{|l|l|l|}
\hline Variable & Banding & $\begin{array}{l}\text { Scores (summed to } \\
\text { create the Ford score) }\end{array}$ \\
\hline Children eligible for free school & & 0 \\
\cline { 2 - 3 } meals as a percentage of all pupils & $5.00-9.99 \%$ & 1 \\
\cline { 2 - 3 } & $10.00-19.99 \%$ & 2 \\
\cline { 2 - 3 } & $20.00-29.99 \%$ & 3 \\
\cline { 2 - 3 } & $30.00-49.99 \%$ & 4 \\
\cline { 2 - 3 } & $>50.00 \%$ & 5 \\
\hline \multirow{4}{*}{$\begin{array}{l}\text { Percentage of all pupils with } \\
\text { needs }\end{array}$} & $0-9.99 \%$ & 0 \\
\cline { 2 - 3 } & $10.00-19.99 \%$ & 2 \\
\cline { 2 - 3 } & $20.00-31.99 \%$ & 4 \\
\cline { 2 - 3 } & $>32.00$ & 6 \\
\hline \multirow{3}{*}{$\begin{array}{l}\text { Unauthorised absence rate as a } \\
\text { percentage of all pupils }\end{array}$} & $0-0.25 \%$ & 0 \\
\cline { 2 - 3 } & $0.26-1.99 \%$ & 1 \\
\cline { 2 - 3 } & $>2.00 \%$ & 2 \\
\hline & & 0 \\
\hline \multirow{2}{*}{$\begin{array}{l}\text { Exclusion rate as a percentage of } \\
\text { all pupils }\end{array}$} & $0-0.79 \%$ & 2 \\
\cline { 2 - 3 } & $0.8-0.99 \%$ & \\
\cline { 2 - 3 } & $>1.00 \%$ & \\
\hline
\end{tabular}

The calculation and interpretation of the Ford score in the 216 independent schools require careful consideration because the component variables of the Ford score do not have identical meanings. In particular, children in independent schools are never eligible for FSM, and so all independent schools automatically score zero on that component of the Ford score. In addition, although a child's statement may occasionally provide a place at an independent school, most independent schools do not apply for statements of SEN, as it does not routinely secure them additional funding. Finally, some independent schools do not report the component variables of the Ford score to DCFS/OfStEd, although this was true of only a minority (40/267) of independent schools in the BCAMHS sample. We therefore present sensitivity analyses below which examine the effect of excluding independent schools from our main sample.

\section{Indices of multiple deprivation}

The English Index of Multiple Deprivation 2004 (IMD 2004) is a small-area measure of neighbourhood deprivation, calculated as the weighted average across seven domains of deprivation using data from the years 2000 to 2003 (Office of the Deputy Prime Minister, 2004). IMD scores have been designed and validated to be calculated at the level of Lower Super Output Areas (LSOAs). LSOAs are geographical units of varying size but containing a population of approximately 1,500 according to the 2001 census (Office of the Deputy Prime Minister, 2007). They aggregate into Middle Super Output Areas (MSOAs), these having a mean population of 7,200 and representing an amalgamation of LSOAs that fit within the 2002 boundaries of local authorities (National Statistics, 2007). For most purposes it is a major advantage of the IMD that deprivation scores are calculated individually for each LSOA, because areas which are geographically close can 
nonetheless vary greatly in their deprivation levels. As such, measures of deprivation aggregated across larger areas may hide pockets of deprivation or affluence. When it comes to using the IMD as a proxy for school deprivation, however, this advantage becomes a potential problem: because LSOAs are generally considerably smaller than school catchment areas, the IMD score of a school's postcode may not be representative of the full area from which it draws its pupils. We therefore adopted a method used by a previous research team investigating the effect of school deprivation upon child health (Bellis et al., 2007). This involved creating an MSOA-level deprivation score by taking the average IMD of its component LSOAs, weighting each LSOA by its total population in mid-2004. For each school in B-CAMHS04 we used its postcode to determine MSOA, and then matched this to the weighted MSOA average which we obtained from Bellis et al.

\section{Statistical analyses}

All analyses were carried out in Stata 9.2, using the svyset command to adjust for the clustered sampling design of the B-CAMHS surveys. Logistic regression was used for analyses which had psychiatric diagnosis as the outcome, while linear regression was used for analyses which had parent, teacher or child SDQ as the outcome.

\section{Results}

\section{The Ford score as a predictor of mental health in schools}

On the seventeen-point Ford score scale the 3,118 schools in the sample scored between 0 and 16, with a mean Ford score of 4.55, standard deviation (s.d.) 3.22. This was lower than in 1999 (mean Ford score 5.61, s.d. 3.10, $p$ value for difference < 0.001), due largely to a decline between 1999 and 2004 in the percentage of children eligible for FSM and the percentage with statemented SEN.

The Ford score was highly predictive of the level of emotional and behavioural difficulties in schools as judged by parent-report SDQ, teacher-report SDQ and the psychiatric diagnosis assigned by psychiatrists, with a linear effect across the whole range (Figures 1-3). The effect sizes were large, with the estimated prevalence of diagnosis rising from about 5 per cent in schools with low Ford scores to around 14 per cent in high-scoring schools. The corresponding odds ratio of psychiatric diagnosis per one-point increase on the Ford score was 1.12 (95 per cent CI 1.09-1.15, $p<0.001$ ). The increase in mean SDQ score per one-point increase on the Ford score was $0.33(0.28-$ $0.38, p<0.001)$ for parents and $0.27(0.22-0.32, p<0.001)$ for teachers. This translates into an overall difference of approximately three points between high- and low-scoring schools, or about half a standard deviation by British norms (www.sdqinfo.com). The association between Ford score and child SDQ was smaller (about a 1.5 point difference in mean SDQ scores between high- and low-scoring schools), and the relationship was less obviously linear (Figure 4). There was nonetheless strong evidence $(p<0.001)$ that higher Ford scores were predictive of higher levels of child-reported psychopathology 
within schools, with an increase in mean child-report SDQ 0.14 per one-point increase on the Ford score (95 per cent CI 0.08-0.21, $p<0.001$ ). All these findings changed very little in a sensitivity analysis using a modified Ford score comprised only of FSM, unauthorised absences and exclusions. (Results available on request.)

Figure 1: Prevalence of psychiatric disorder (average prevalence and $95 \%$ confidence intervals) by school's Ford score

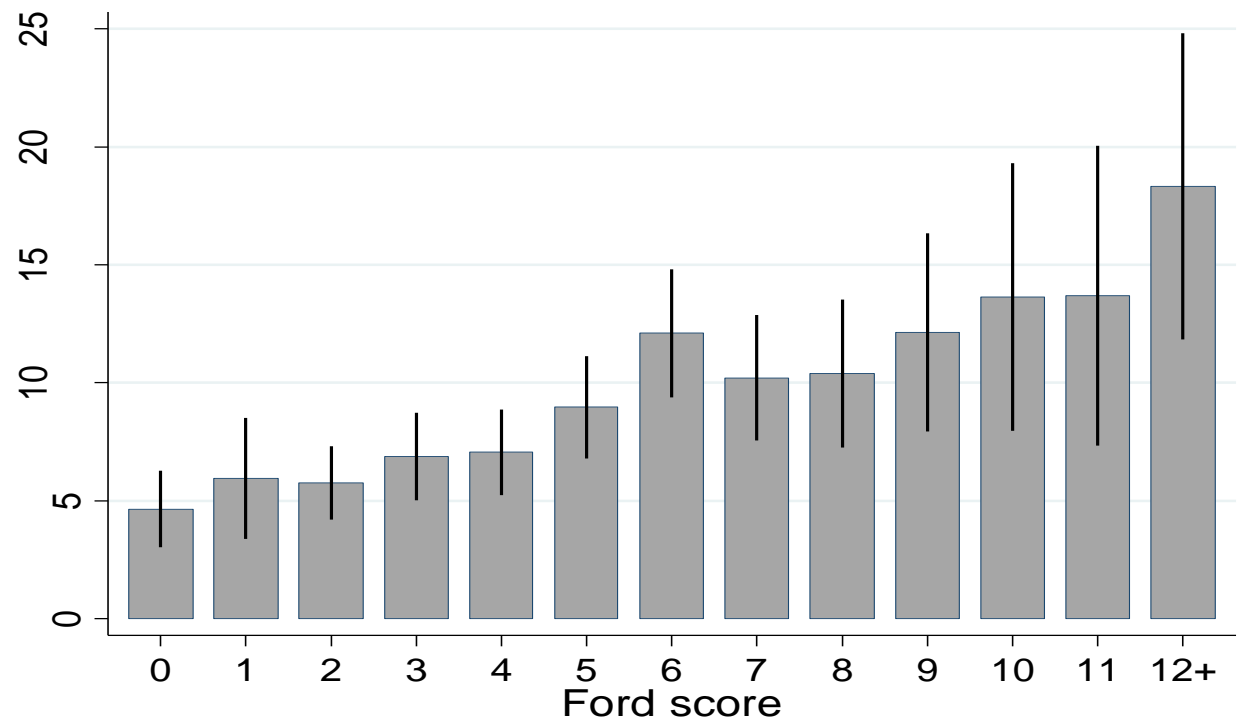

Figure 2: Parent-report total difficulties SDQ score (mean score and $95 \%$ confidence intervals) by school's Ford score

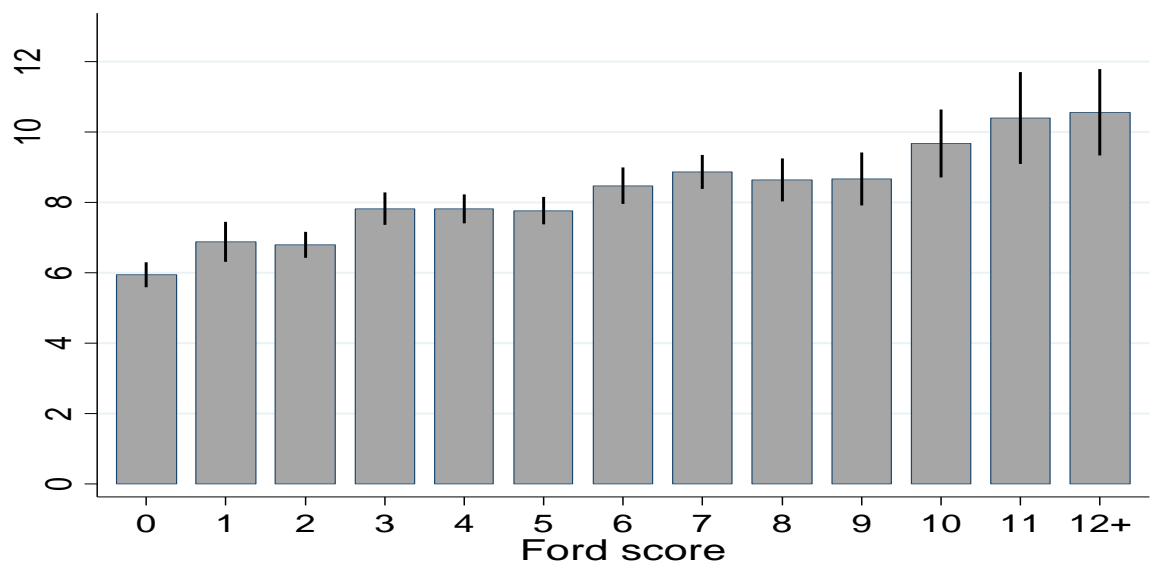


Figure 3: Teacher-report total difficulties SDQ score (mean score and 95\% confidence intervals) by school's Ford score

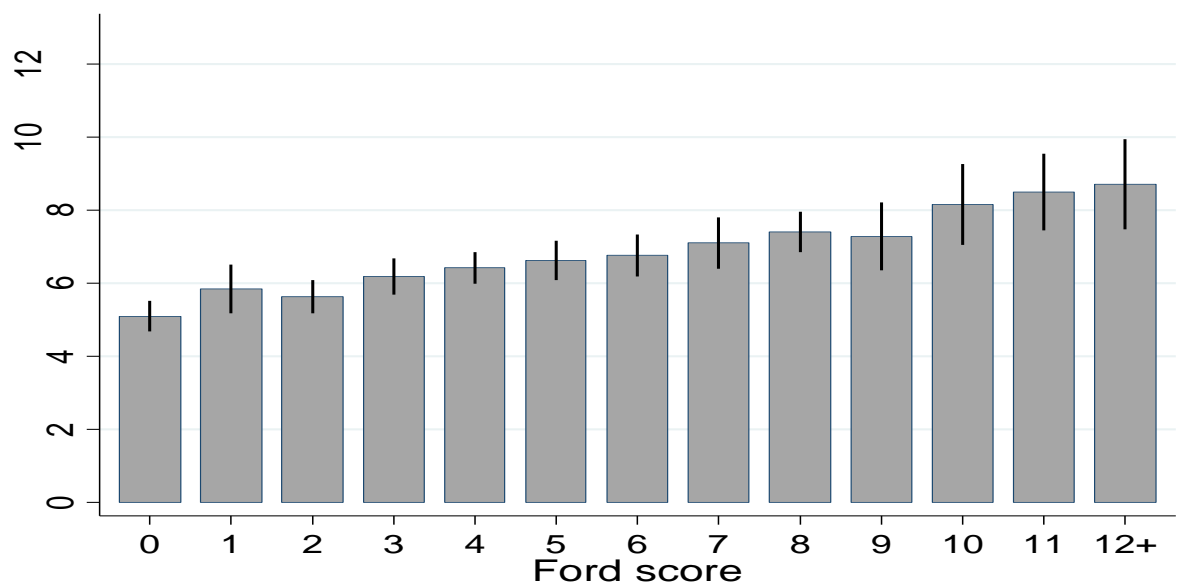

Figure 4: Child-report total difficulties SDQ score (mean score and $95 \%$ confidence intervals) by school's Ford score

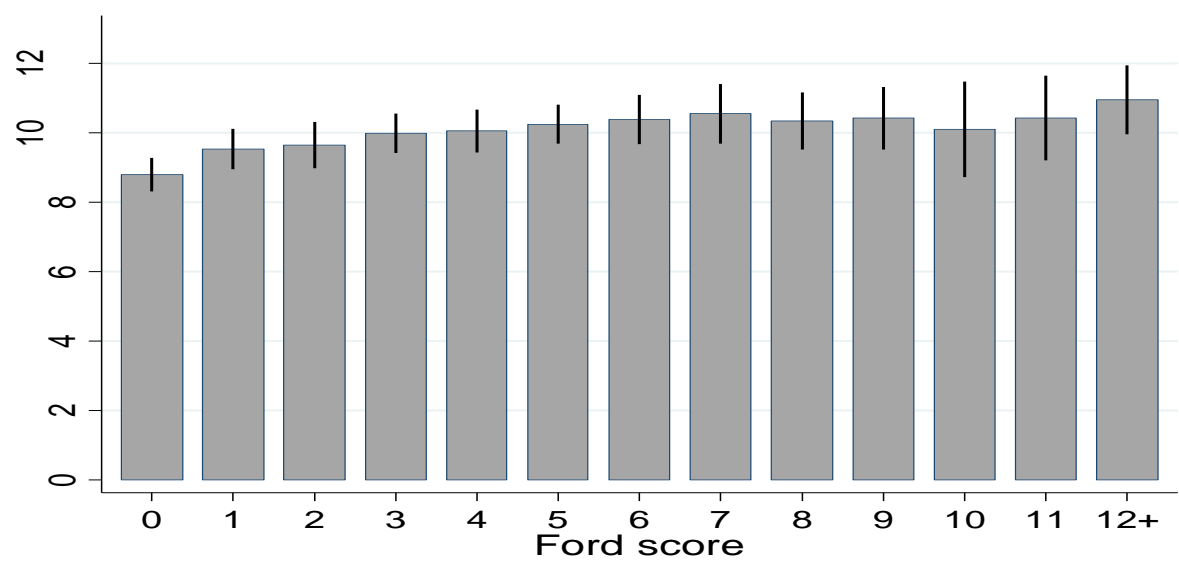

Table 2 compares the Ford score with the proportion of pupils entitled to FSM, demonstrating that the Ford score was more highly correlated with all measures of psychopathology than FSM. When FSM was entered into regression models simultaneously with the Ford score, the Ford score continued to be highly predictive of all outcomes while the effect size of FSM was small and non-significant $(p>0.1)$ for psychiatric diagnosis, parent SDQ or teacher SDQ. For child SDQ the effect of FSM was statistically significant $(p=0.007)$ but higher FSM predicting lower child SDQ. This was in the opposite direction to what would be expected and to what was shown in univariate regression models in which FSM alone was entered. This unexpected negative association suggests that FSM may be a less important predictor of self-report psychopathology than the other component variables of the Ford score, which therefore 'overcorrects' for Ford score when both are entered into a regression model simultaneously. 
Table 2: Correlations of 1) the percentage of children eligible for free school meals 2) the Ford score and 3) the school's MSOA-level IMD average, with SDQ total difficulties scores reported by parents, teachers and children.

\begin{tabular}{|l|l|l|l|}
\hline & $\begin{array}{l}\text { Parent-report total } \\
\text { difficulties score } \\
(\mathrm{N}=6,340)\end{array}$ & $\begin{array}{l}\text { Teacher-report total } \\
\text { difficulties score } \\
(\mathrm{N}=5,044)\end{array}$ & $\begin{array}{l}\text { Child-report total } \\
\text { difficulties score } \\
(\mathrm{N}=2,761)\end{array}$ \\
\hline $\begin{array}{l}\text { Percent pupils eligible } \\
\text { for free school meals }\end{array}$ & 0.156 & 0.111 & 0.038 \\
\hline Ford score & 0.178 & 0.140 & 0.090 \\
\hline $\begin{array}{l}\text { MSOA-level IMD } \\
\text { average }\end{array}$ & 0.109 & 0.082 & 0.002 \\
\hline
\end{tabular}

Ford scores for the 216 independent schools were in the range $0-6$, with a mean of 1.00 (s.d. 1.43) and with 132 schools (61 per cent) scoring zero. Sensitivity analysis which repeated the analyses described in the previous section after excluding independent schools shows that this made very little difference to the value presented and no difference to the pattern of the results - an unsurprising finding, given that the independent schools account for under 5 per cent of the children analysed in this article. The small number of independent schools meant we were underpowered to analyse that group separately, even using the dimensional SDQ scores

\section{The Index of Multiple Deprivation}

The 3,117 schools in our sample had MSOA-level IMD averages which ranged from 1.8 to 77.8, with a mean of 21.4. The correlation between a school's MSOA-level IMD average and the (standard) LSOA-level IMD score for its B-CAMHS participant pupils was 0.705 . The MSOA-level IMD averages were positively skewed, but our substantive findings were identical whether we used raw scores, scores which had been transformed using a zero-skew log transformation or scores banded into deciles. We therefore present findings from the raw scores in this article.

MSOA-level IMD averages were predictive of any disorder, parent SDQ and teacher SDQ $(p<0.001)$, with higher deprivation being associated with poorer mental health. MSOA-level IMD average showed no association with child SDQ $(p=0.982)$. The correlation of MSOA-level IMD averages with SDQ scores was, however, substantially lower than either FSM or the Ford score (see Table 2). In multiple regression models including both Ford score and MSOA-level IMD the Ford score continued to be highly predictive of all outcomes ( $p<0.001$ in all cases) while MSOA-level IMD became highly non-significant for any disorder, parent SDQ and teacher SDQ alike ( $p>0.3$ in all cases).

\section{$\underline{\text { Discussion }}$}

This paper uses data from the 2004 British Child and Adolescent Mental Health Survey (B-CAMHS04) to provide the first independent validation of the Ford score. Our data suggest that a school's Ford score is strongly associated with the level of emotional and behavioural difficulties in its pupils. The difference between schools with high Ford scores and schools with low Ford scores is large and reasonably linear across the whole 
range, the predictive power of the Ford score being particularly strong for psychiatric diagnosis, parent SDQ and teacher SDQ. Our data further demonstrate that all measures of child psychopathology are more highly correlated with the Ford score than with the proportion of children receiving FSM. This indicates that the Ford score represents an advance over simply using proportion FSM as a school-level predictor of emotional and behavioural difficulties.

These findings are very similar to those of the preliminary assessment of the Ford score using data from B-CAMHS99 (Ford and Goodman, 2005). These analyses represent an important advance, however, because they avoid the circularity of judging the Ford score against the same data used to derive it. Our analyses also expand on those reported in the original creation of the Ford score by assessing whether school-level deprivation, as measured using the MSOA-level IMD average of the school, makes a useful addition to the predictive properties of the Ford score. MSOA-level average was highly associated with most measures of child mental health in univariate analyses. It became highly nonsignificant, however, when entered simultaneously with the Ford score in regression models. We therefore conclude that MSOA-level IMD average would not make a useful addition to the Ford score.

The lack of an independent effect from MSOA-level IMD score also suggests that the deprivation of a school's area may not have a direct effect upon child mental health. This may be because the deprivation of a school's area is correlated with a school's Ford score but does not itself have a causal effect on a child's mental health. Alternatively, a school's area deprivation may have a causal effect but one which is mediated by the variables measured in the Ford score rather than independent of it. For example, a school's area deprivation might be harmful because it led to higher rates of unauthorised absences, which in turn were associated with poor child mental health. This null finding may also be partly attributable to deficiencies in MSOA-level IMD average as a measure of school deprivation.

It is reassuring that the Ford score continues to work well despite evidence of a downward secular trend in the mean Ford score between 1999 and 2004. This indicates that even though, for example, the absolute frequency of statementing for SEN may have declined over this time, the predictive power of being in a 'high' SEN school compared with a 'low' SEN school has not been seriously compromised. It is, however, possible that the Ford score will need to be recalibrated or otherwise modified for more recent data and into the future, particularly for the statemented SEN and FSM variables. With regard to statemented SEN, statementing practice in schools has been changing since 2004, with the adoption of a graduated approach to special education needs which starts with 'school actions' (unstatemented), progresses to 'school action plus' (unstatemented, but with the involvement of external professionals) and then, finally, 'statemented SEN'. SEN provision is paid for from allocated school budgets regardless of whether the child is statemented or not, and statementing a child's SEN usually brings additional funds only for the most severe cases (as judged by number of hours' individual support). As a result, there now exists relatively little incentive for schools to statement many children with SEN (Judd, 2007). It may therefore be better to replace the 
statemented SEN variable with sum total of pupils who have school actions, school actions plus and statemented SEN. (These variables are now being collected in the annual schools census). Alternatively, given that a modified Ford score without SEN gave very similar results to the full Ford score, it may be possible to drop SEN altogether if its inclusion proved problematic through creating perverse incentives.

With regard to FSM, while this is still widely used at present, schools will shortly be encouraged to shift to using data based upon entitlement to working and/or child tax credit as a measure of deprivation instead. At present it is planned to make these data available at the pupil level only, with local authorities and schools creating school-level averages themselves (Judd, 2007). These data would therefore not routinely be available to researchers. If, however, DCSF were routinely to create school-wide averages for tax credit entitlement for all schools, then it would be worth exploring whether this represented an improvement over FSM in the Ford score.

This article has several important strengths, including a large and nationally representative selection of English schools, and the ability to make use of four well validated measures of mental health from three separate informants. There are, however, also some important limitations to both the data we had and the methodology we used. Our sample of independent schools was small (216), meaning that we did not have sufficient power to assess whether the Ford score works well in that group. Given that FSM is always zero in independent schools, however, it certainly seems plausible that the Ford score represents an improvement in terms of predicting the mental health of children in independent schools, and we hope future research will address this question. A further limitation is the measure we use of school deprivation. Middle super output area (MSOA)-averaged IMD scores are relatively highly correlated with the lower super output area (LSOA)-level IMD of individual children, and give plausible associations with the level of child mental health problems in schools. They have not, however, yet been validated as a measure of MSOA deprivation. Moreover, even though the predictive power of the Ford score is not improved by the inclusion of MSOA-averaged IMD, it might be improved by a more precise measure such as the school-wide average of the LSOA-level IMD scores of individual pupils. This more precise measure of school deprivation is not routinely collected or publicly available, however, and is therefore not generally an option for researchers.

\section{Conclusion}

Several features of the Ford score makes it attractive for academic research. It can be obtained using only school postcode as a starting point, and is composed of data which are reported annually (rather than, for example, information which only updated every three or four years during an OfStEd inspection). It therefore represents a feasible way of obtaining a simple and up-to-date school mental health predictor which we have demonstrated to be more accurate than FSM alone and not notably improved by adding in a school's MSOA-level deprivation. 
This does not mean that the Ford score will be suitable for all purposes. Local authorities may be rightly cautious of creating undesirable incentives by adopting a measure which includes within its constituent variables some factors such as the percentage of pupils with statemented SEN which it is within the school's power to influence. Local authorities may also wish to explore further the added value which may be possible using deprivation measures which are based on an actual IMD average based on all pupils in school. Nevertheless, we suggest that the Ford score may prove useful for academic researchers as a predictor of mental health in schools, and perhaps also for other purposes such as forecasting need for services.

\section{Conflict of interest}

None

\section{Acknowledgements}

Many thanks to Andrew McKechnie and our other colleagues at OfStEd and the Department for Children, Schools and Families for their help in matching schools to the component variables of the Ford score. Thanks also to ONS Geography for matching schools to their MSOA on the basis of postcode and to Karen Tocque and her colleagues at Liverpool John Moores University for supplying us with the MSOA-level IMD averages used in this article.

\section{$\underline{\text { References }}$}

Bellis, M. A., Hughes, K., Morleo, M., Tocque, K., Hughes, S., Allen, T., Harrison, D., and Fe-Rodriguez, E. (2007), 'Predictors of risky alcohol consumption in schoolchildren and their implications for preventing alcohol-related harm', Substance Abuse Treatment, Prevention and Policy 2, 15.

Collishaw, S., Maughan, B., Goodman, R., and Pickles, A. (2004), 'Time trends in adolescent mental health', Journal of Child Psychology and Psychiatry 45 (8), 135062.

Daniels, H., Visser, J., Cole, T., and de Reybekill, N. (1999), Emotional and Behavioural Difficulties in Mainstream Schools, Research Report 90, London: HMSO.

Department for Education and Skills (1997), Excellence in Schools, London: HMSO.

- (2005), Child Poverty: Fair Funding for Schools, London: DfES/Treasury.

- (2006), Technical Review of Deprivation Indicators (September 2006). Available (26 February 2008) at www.teachernet.gov.uk.

- (2007), 'Special educational needs in England, January 2007', National Statistics First Release: SFR 20/2007, London: Department for Education and Skills.

Ford, T. and Goodman, R. (2005), 'The Ford score: a simple measure for predicting the level of emotional and behavioural problems within mainstream schools', Emotional and Behavioural Difficulties 10, 219-33.

Ford, T., Goodman, R., and Meltzer, H. (2003), 'The British Child and Adolescent Mental Health Survey, 1999: the prevalence of DSM-IV disorders', Journal of the American Academy of Child and Adolescent Psychiatry 42 (10), 1203-11. 
Ford, T., Hamilton, H., Meltzer, H., and Goodman, R. (2007), 'Child mental health is everybody's business; the prevalence of contacts with public sector services by the types of disorder among British schoolchildren in a three-year period', Child and Adolescent Mental Health 12, 13-20.

Goodman, R. (1997), 'The Strengths and Difficulties Questionnaire: a research note', Journal of Child Psychology and Psychiatry 38 (5), 581-6.

- (2001), 'Psychometric properties of the Strengths and Difficulties questionnaire', Journal of the American Academy of Child and Adolescent Psychiatry 40 (11), 133745.

Goodman, R., Ford, T., Richards, H., Gatward, R., and Meltzer, H. (2000), 'The Development and Well-being Assessment: description and initial validation of an integrated assessment of child and adolescent psychopathology', Journal of Child Psychology and Psychiatry 41 (5), 645-55.

Graham, P. (2000), 'Mental health must be "centre stage" in child welfare', Archives of Disease in Childhood 83 (1), 4-7.

Green, H., McGinnity, A., Meltzer, H., Ford, T., and Goodman, R. (2005), Mental Health of Children and Young People in Great Britain, 2004, Palgrave: Macmillan.

Hendry, J. (2000), Who Holds the Purse? Funding Schools to meet Special Educational Needs, Slough: National Foundation for Educational Research.

Judd, M. (2007), personal communication during meeting at the Department for Children, Schools and Families, 17 October 2007.

Marsh, A. (1997), Current Practice for Resourcing Additional Educational Needs in Local Educational Authorities, Slough: National Foundation for Educational Research.

Meltzer, H., Gatward, R., Goodman, R., and Ford, T. (2000), Mental Health of Children and Adolescents in Great Britain, London: Stationery Office.

National Statistics (2007), Super Output Areas (SOAs): Frequently Asked Questions. Available (26 September 2007) at www.statistics.gov.uk/geography/soa.asp.

Office of the Deputy Prime Minister (2004), The English Indices of deprivation, 2004: Summary (Revised). Available (26 February 2008) at www.communities.gov.uk.

-(2007), Indices of Deprivation, 2004: Population Denominators. Available (26 February 2008) at www.communities.gov.uk.

Rutter, M., and Smith, D. J., eds (1995), Psychosocial Disorders in Young People, Chichester: Wiley.

World Health Organisation (1993), The ICD-10 Classification of Mental and Behavioural Disorders: Diagnostic Criteria for Research, Geneva: World Health Organisation.

-(2003), Caring for Children and Adolescents with Mental Disorders, Geneva: World Health Organisation. 